\title{
ARCHIVALIA BETREFFENDE DE VOORMALIGE \\ NEDERLANDSE KOLONIËN ESSEQUEBO, DEMERARY EN BERBICE IN HET \\ PUBLIC RECORD OFFICE TE LONDEN
}

Bij een bezoek aan het Public Record Office eind september I96o bleek mij, dat in de inventaris van de Colonial Office Papers onder het Hoofd C.O. Ir6/18-136, een verzameling Nederlandse stukken wordt vermeld, die betrekking hebben op de voormalige Nederlandse koloniën Essequebo, Demerary en Berbice, het tegenwoordige Brits Guyana. Deze archivalia worden in de inventaris aangeduid als "Dutch Association papers" en "Berbice".

Een onderzoek van de originele stukken zelf, dat zich uiteraard tot enige steekproeven moest beperken, bracht aan het licht, dat het hier in de eerste plaats gaat om originele brieven en bijlagen door het bestuur in Essequebo en Demerary gezonden aan de kamer Zeeland van de West Indische Compagnie (C.O. II6/I8-67), terwijl de nummers 68-136 een deel van het archief der directie van Berbice omvatten, nl. de van daar naar Nederland verzonden stukken. Een vergelijking van deze beschrijving met die van de archivalia over deze koloniën in de inventaris van de West Indische Compagnie en het directie-archief, toont aan, dat de zich in het Public Record Office bevindende stukken juist ontbreken in de reeksen van het Algemeen Rijksarchief.

De functionarissen van het Public Record Office konden geen verklaring geven, hoe deze Nederlandse documenten daar terecht waren gekomen. $Z_{i j}$ toonden zich zeer verbaasd over de aanwezigheid daarvan in hun archieven. Wel wezen zij mij een passage in de inleiding van een der Calendars of State Papers (Colonial Series, America and West Indies, I700, in welk deel enkele Nederlandse stukken uit het Public Record Office in Engelse vertaling zijn uitgegeven), die een aanwijzing kon bevatten voor de herkomst.

In 1892 stelde $\mathrm{H}$. BRUGMans in opdracht van de Nederlandse regering een onderzoek in naar archivalia betreffende de Nederlandse geschiedenis in Engelse archieven. Maar kennelijk heeft 
hij niet de inventaris van de stukken van het Colonial Office geraadpleegd. In zijn verslag is althans niets over de bovengenoemde archivalia te vinden.

Toch is de historische literatuur over de Britse bezittingen in Guyana niet onbekend met de aanwezigheid van deze stukken in het Public Record Office.

Ter bijlegging van een grensgeschil tussen Venezuela en Engeland over de grens van Brits Guyana met Venezuela in het eind van de Igde eeuw, was door de president van de Verenigde Staten een commissie benoemd voor een onderzoek ter plaatse en in de archieven. Het resultaat van die onderzoekingen is neergelegd in enige lijvige rapporten met bijlagen, in I897 gepubliceerd (Report and accompanying papers of the Commission appointed by the president of the United States to investigate and report upon the true divisional line between the Republic of Venezuela and British Guiana, Washington, 9 vols. I897). Alleen vol. I (historical reports) en vol. II (extracts from archives) en vol. V en VI, British Blue Books, Venezuela, I-V, zijn voor de Guyanastukken van belang. Het onderzoek in de archieven van de West Indische Compagnie in den Haag werd verricht door de Amerikaanse professor G. L. BURR, die hiertoe in 1896 zeven maanden op het Algemeen Rijksarchief werkte. Burr kon zich bij zijn onderzoek bepalen tot de archieven betreffende de kolonie Essequebo. Al spoedig bemerkte hij, dat er grote hiaten in de series waren "whose loss threatened to be most serious of all" (Report I, p. I24). Door de gelijktijdige uitgave van Engelse zijde van de genoemde Blue Books, die grotendeels extracten bevatten van de Nederlandse stukken in Engeland, ontdekte Burr op welke wijze deze grote hiaten in de West Indische archieven in den Haag waren aan te vullen. Hij zette zijn onderzoekingen dan ook verder te Londen voort. In zijn rapport geeft hij een korte beschrijving van deze documenten in het Public Record Office (I, p. I29-I30) en hij acht deze series van originelen met bijlagen veel completer dan die in den $\mathrm{Haag}$. $\mathrm{Al}$ is het ook Burr duidelijk dat deze stukken oorspronkelijk behoorden tot het archief van de Kamer Zeeland, in de motieven van de afgifte verdiept hij zich niet en hij veronderstelt slechts, dat in I8I4 bij de overgave van de kolonie de Nederlandse regering tegelijk aan de Engelsen heeft overgeleverd "its own best official set of these colonial papers" (I, p. I30).

De toenmalige ambtenaren van het Algemeen Rijksarchief, van wie in het bijzonder Mr. A. Telting Burr terzijde stond, ver- 
wonderden zich niet minder dan de Amerikaanse geleerde over deze ontdekking, maar schijnen het verder bij deze verwondering te hebben gelaten.

Tot dank voor de hulp aan Burr bij zijn onderzoek door de ambtenaren van het Algemeen Rijksarchief bewezen, bood de Britse regering in I90o de Algemene Rijksarchivaris een zilveren inktkoker met toepasselijke inscriptie aan, die in dank werd aanvaard (Corr. Alg. Rijksarchief, uitgaande brieven 26/II I900, 40r). Een geschenk, dat de herinnering kon wakker houden aan de voor Nederland onbereikbare archivalia in Engeland.

Bijzonder onaangenaam moet de ontdekking van de stukken voor P. M. Netscher zijn geweest, die, al was hij geen ambtenaar aan het Algemeen Rijksarchief, eveneens zijn hulp aan Prof. Burr had verleend. Netscher had juist enkele jaren tevoren (in I888) zijn Geschiedenis van de koloniēn Essequebo, Demerary en Berbice gepubliceerd, ongetwijfeld een zeer verdienstelijk werk, dat nog steeds geldt als het meest gezaghebbende voor de geschiedenis van de voormalige Nederlandse koloniën in de West. Netscher baseerde zijn studie echter uitsluitend op de bronnen in het Algemeen Rijksarchief, onkundig als hij was van het feit, dat ongeveer I20 delen van die archieven te Londen berustten. In tegenstelling tot Burr, waren Netscher blijkbaar niet de hiaten in de archieven opgevallen. Zelfs spreekt hij over het zeer complete archief van de directeuren van Berbice (Netscher, p. 87).

Behalve op archiefmateriaal, steunt Netscher ook op gedrukte literatuur, o.a. op het werk over de Nederlandse bezittingen in Guyana door J. J. HARTSINCK (Amsterdam, I770). Hartsinck zou voor zijn studie ook oude archieven hebben geraadpleegd. Hij althans kan die archieven nog in ongeschonden staat hebben aangetroffen.

Het reeds genoemde rapport met bijlagen over het grensgeschil beperkte zich voor de periode na 1674 strikt tot gegevens over deze grens. Vóór I674 werden echter ook stukken opgenomen, die meer in het algemeen de territoriale rechten van de Nederlandse West Indische Compagnie in Guyana betroffen. In het tweede deel van het rapport, dat de extracten uit archieven bevat, zijn dus voor de eerste keer in een moderne publicatie de stukken over Guyana in het Algemeen Rijksarchief in den Haag tezamen uitgegeven met die in het Public Record Office, zij het voor een beperkt doel.

Enige jaren later bracht deze uitgave C. A. Harris en J. A. J. DE VILLIERS op het denkbeeld de opkomst en uitbreiding van het 
tegenwoordige Brits Guyana, zoals deze bij Netscher zijn beschreven, aan te vullen uit de stukken, die in Engeland berusten. $\mathrm{Zij}$ concentreerden hun onderzoek om de bekwame gouverneur van Essequebo en Demerary, LaURens Storm van 's GraveSANDE. Hun publicatie kreeg de vorm van een keuze uit de brieven van Storm van 1738 tot 1772 . Uit de elf omvangrijke bundels, die deze brievencollectie in het Public Record Office omvat, is in verhouding slechts een klein gedeelte, in extenso en in extract, in Engelse vertaling gepubliceerd. Het is opgenomen in twee delen van de werken van de Hakluyt Society (second series, vol. XXVI, XXVII, London, I9II).

Harris en de Villiers hebben voor hun inleiding en annotatie, voor zover na te gaan, geen aanvullend archiefonderzoek in het Algemeen Rijksarchief in den Haag verricht. $\mathrm{Zij}$ baseren zich op Netscher en op de stukken te vinden in de bijlagen tot het rapport van de grensgeschilcommissie. Beide publicaties, die van de grensgeschilcommissie en die over Storm van 's Gravesande door Harris en de Villiers, geven dus slechts een beperkte keuze uit het rijke materiaal van de twee archiefbestanddelen in den Haag en in Londen.

Weinig blijkt men in Engeland op de hoogte te zijn geweest van de omstandigheden, die hebben geleid tot deze afstand van origineel archief-materiaal door Nederland, geheel ingaande tegen het principe van het 'respect des fonds.'

In de reeds genoemde inleiding tot de Calendar of State Papers (Colonial Series, America and West Indies, ed. by Cecil Headlam, London I9IO) wordt op p. VIII een brief geciteerd, die zich bevindt in een der indices op een gedeelte van de Nederlandse Guyana-stukken in het Public Record Office (C.O. II6/67) en waarin de afstand door Nederland van een gedeelte, in het bijzonder van de archivalia betreffende Berbice, wordt vermeld. Deze brief dd. I6 maart I8I9 is geschreven door RoBerT MELvill, Brits Consul te Amsterdam, aan de Secretary of State for the Colonies, Lord BATHurst. Naar aanleiding van dit formele briefje, dat geen nadere bijzonderheden bevat, oppert de bewerker van de Calendar enige veronderstellingen over de mogelijke aanleiding tot de afgifte, maar hij verdiept zich verder niet in deze zaak.

Een onderzoek in de diplomatieke correspondentie van de Britse gezant in Nederland, de Earl of ClanCARTY aan de minister van buitenlandse zaken CASTLEREAGH, te vinden in het ar- 
chief van het Foreign Office in het Public Record Office, leverde wel is waar enige gegevens, maar pas door een aantal brieven en bijlagen, berustend in de archieven van de tweede afdeling van het Algemeen Rijksarchief, die dank zij de heer J. STEUR werden samengebracht, was het mogelijk hetgeen had plaats gehad geheel te reconstrueren.

Noch in het verdrag van $\mathrm{I}_{3}$ augustus $\mathrm{I}_{8} \mathrm{I}_{4}$, waarbij de definitieve afstand aan Engeland van de Nederlandse koloniën Essequebo, Demerary en Berbice werd geregeld (E. G. LAGEMANS, Recueil des traités et conventions conclus par le royaume des Pays Bas avec les puissances étrangers depuis I813, I, La Haye, I858, p. 34-38), noch in de additionele artikelen (p. 38-40), komt een bepaling voor over de afstand van de archieven van deze koloniën aan Engeland.

Op 27 december $18 \mathrm{I} 7$ echter richtte de Britse gezant in den Haag, Clancarty, zich tot de Nederlandse minister van buitenlandse zaken, baron vaN NAGELL (arch. B. Z. I53), met de mededeling, dat hij van zijn regering een instructie had ontvangen, de afstand te eisen van de archieven en andere officiële documenten betreffende de vestigingen in Demerary, Essequebo en Berbice. Deze afgifte werd wenselijk geacht wegens "the necessity of having frequent and immediate references to the records of these settlements and the absence of such necessity, as applicable to this [het Nederlandse] government". De stukken betreffende die koloniën zouden nog berusten onder de West Indische Compagnie te Middelburg.

Het is niet verwonderlijk, dat Clancarty niet op de hoogte was van de ingewikkelde organisatie van het bestuur over de Nederlandse West Indische koloniën en daardoor ook niet van de archieven, die van deze besturen afkomstig waren. Als gevolg van die onkunde bleef zijn eis beperkt tot de stukken, die in Zeeland berustten. Noch wist hij van het bestaan van een hoofddirectie te Amsterdam, noch van de verschillende kamers, van welke de kamer Zeeland er slechts een was. Evenmin was hij toen reeds op de hoogte van het feit, dat Berbice bestuurd was geworden niet door de West Indische Compagnie, maar door een afzonderlijke directie, die te Amsterdam gevestigd was geweest.

De Nederlandse autoriteiten bleken niet veel beter op de hoogte, maar ernstiger is het, dat zij, met uitzondering van de directeur-generaal van koophandel en koloniën, JoHANNES GOLDBERG, en van een ondergeschikte ambtenaar in de provincie Zeeland, niet de minste belangstelling voor deze zaak hebben 
gehad. Zowel Goldberg als bovengenoemde ambtenaar hebben getracht met deugdelijke argumenten de afstand van de stukken te verhinderen. Het reeds spoedig gevolgde aftreden van Goldberg (I9 maart I8I8) door de samenvoeging van zijn departement met dat van onderwijs, kunsten en wetenschappen tot een departement voor het publiek onderwijs, de nationale nijverheid en de koloniën, dat onder beheer van A. R. FALCK werd gesteld, maakte echter aan zijn bemoeiingen te spoedig een eind.

Door de Nederlandse minister van buitenlandse zaken, Van Nagell, was de brief van Clancarty voor advies aan de Koning overgedragen aan het departement van koophandel en koloniën (29/12 I8I7, B. Z. 307). Goldberg liet daarop een onderzoek instellen in het archief van de voormalige kamer der West Indische Compagnie te Middelburg (Goldberg aan de minister van buitenlandse zaken 31/12 I8I7, B. Z. I54).

Dit onderzoek werd verricht door de oud-commissaris bij het voormalige koloniale etablissement te Middelburg, W. C. LAMBRECHTSEN. Uit diens brief van 20 januari I8I8 aan het ministerie van koophandel en koloniën (Arch. Kol. I73), blijkt, dat deze ambtenaar de draagwijdte van het Engelse verzoek terdege heeft begrepen. Hij geeft daarom zijn brief aan Goldberg een meer privé karakter, terwijl hij voorstelt in een officieel schrijven geen melding te maken van de aanwezigheid van de belangrijkste stukken, in het bijzonder van de notulen door het bestuur in de koloniën gehouden en in copie naar de kamer in Nederland gezonden. Lambrechtsen toont inzicht te hebben in de principes, die bij de afstand van archivalia moeten gelden. Hij toch wijst erop, dat men, vóór tot afgifte van stukken aan Engeland over te gaan, zich op de hoogte dient te stellen van wat de Engelsen hebben gedaan met de archieven, die zij in de afgestane koloniën aantroffen, de archieven dus, gevormd door de regering in de koloniën zelf en het interne bestuur aldaar betreffende. Bovendien vraagt hij zich af, hoe de gang van zaken is geweest bij de teruggave aan Nederland van de koloniën, die tijdelijk door Engeland bezet zijn geweest, b.v. Suriname en Curaçao. Al wordt in deze brief nog niet de gevolgtrekking gemaakt, dat Engeland alleen recht kan laten gelden op de archieven, die in de door Nederland afgestane koloniën zijn gevormd en daar zijn blijven berusten, toch wijzen de aangevoerde argumenten wel degelijk in die richting.

Aan tekeningen en kaarten van rivieren en de daaraan gelegen plantages scheen men in Zeeland minder waarde te hechten. 
Lambrechtsen stelt voor twee van zulke in zwarte lijsten geencadreerde kaarten van Demerary aan Engeland af te staan, vooral omdat hij meent dat er betere kaarten bestaan.

In het advies van 5 februari I8I8, dat Goldberg aan de Koning uitbrengt (Staatssecretarie 565) valt de meeste nadruk op het feit, dat zich in handen van de Engelsen de in de afgestane koloniën berustende archieven bevinden. Goldberg keurt bovendien de afstand van de stukken uit de archieven in Nederland af, daar men niet nauwkeurig op de hoogte is van de inhoud van die archieven, welke evenzeer Nederlandse koloniën kunnen betreffen, die niet aan Engeland zijn afgestaan. Goldberg adviseert de Koning dus, dat men de Britse regering zal antwoorden, dat in Nederland alleen die stukken aanwezig zijn, die gediend hebben voor de administratie van de Compagnie in Nederland, stukken van geen belang voor de Britse regering, terwijl het Nederlandse gouvernement zich bij een afstand van die documenten zou beroven van bewijsmateriaal in geval van aanspraken in rechte.

Als bijlage sluit Goldberg een lijst in van de stukken betreffende Essequebo en Demerary en hij wijst op het feit, dat geen archieven betreffende Berbice te Middelburg zijn bewaard. Het aantal van de in deze lijst genoemde delen (52) komt niet overeen met het aantal nog aanwezige delen in het Public Record Office, maar dit is blijkbaar een gevolg van de splitsing van enkele delen.

Op Goldberg's rapport met de volgens moderne opvattingen zo deugdelijke argumenten, wordt door de minister van buitenlandse zaken Van Nagell in zijn advies aan de Koning (ro/2 I8I8, no. 43 , Staatssecr. 565) op wel zeer denigrerende wijze gereageerd. Van het principe van het 'respect des fonds' blijkt deze diplomaat niets te begrijpen. Volgens hem is Engeland door de afstand van de bedoelde koloniën door Nederland gerechtigd tot het bezit van alle documenten, die deze koloniën betreffen, ofschoon, zoals hij moet toegeven, daarover in het tractaat van afstand geen bijzondere bepalingen zijn gemaakt. En wat het juridische argument betreft, eventueel benodigde inlichtingen voor rechtskwesties kunnen evengoed bij de Britse als bij de Nederlandse regering worden aangevraagd. Maar wat voor Van Nagell het meeste weegt: men moet voor alles nodeloze discussies met de Britse regering vermijden en haar daarom zoveel mogelijk ter wille zijn. Als enig voorbehoud adviseert Van Nagell de Koning om door het departement van koophandel en koloniën een onderzoek te laten instellen of de over te dragen 
verzameling stukken bevat, welke betrekking hebben op koloniën, die in het bezit van Nederland gebleven zijn.

Daar het ondoenlijk is uit de gebonden delen archivalia uit te scheiden, stelt de Koning voor van eventueel in aanmerking komende stukken afschriften te doen vervaardigen (I2/2 I8I8 no. 93, Staatssecr. 565). Weer wordt door Goldberg de ambtenaar Lambrechtsen ingeschakeld, die heel weinig voor deze vrij onmogelijke taak voelt, hoewel hij de enige is, door zijn vroegere functie nog enigermate met de West Indische archieven vertrouwd. Hij probeert zich aan de opdracht te onttrekken en adviseert alle delen naar den Haag te laten overbrengen. Daar kunnen zij dan door een ervaren persoon stuk voor stuk worden nagezien, een arbeid, die ongetwijfeld maanden zou duren. Maar van zulk een schifting verwacht Goldberg weinig heil. In zijn laatste adviesbrief beperkt hij zich ertoe het geringe belang van deze documenten voor de Britse regering te onderstrepen en de schending van de Nederlandse archieven bij de afstand aan Engeland. Als tussenweg zou Engeland wellicht nog een opgave kunnen doen van de archivalia betreffende de voormalige Nederlandse koloniën, die ontbreken in de archieven, welke Engeland reeds in handen waren gevallen bij de overgave van de koloniën. Alleen die ontbrekende stukken zouden dan door de

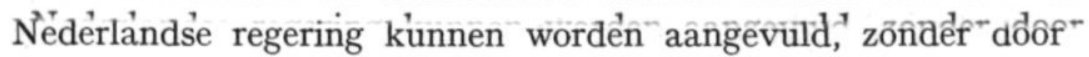
een "overtollige zending het Nederlandsche gouvernement nodeloos van charters te beroven, die de regering in rechte nog zou kunnen nodig hebben" (Goldberg aan minister B.Z. 6/3 I8I8, B.Z. I58). Het was een concessie, waarbij ook Goldberg reeds iets van het 'respect des fonds' losliet. Enige dagen later trad hij af, zijn opvolger Falck heeft kennelijk geen enkel belang meer aan de kwestie gehecht.

Om aan het verzoek van de Koning te kunnen voldoen, werden te Middelburg twee commiezen belast met het onderzoek van de archieven betreffende Essequebo en Demerary, die nog steeds onder de rentmeester van 's Rijks domeinen waren blijven berusten en dus niet naar den Haag waren overgebracht. De beide ambtenaren moesten deze archieven doorzien op documenten afkomstig van andere West Indische koloniën. Het blijkt niet hoe dezen zich van die taak hebben gekweten. $\mathrm{Zij}$ moeten inderdaad alleen gelet hebben op de stukken afkomstig van en niet betreffende de andere koloniën. Immers over Suriname zullen zeker genoeg gegevens in de bewuste Guyana papieren te vinden zijn geweest. Het resultaat, dat verkregen werd, was in ieder 
geval volkomen negatief. Zowel voor de moeite van het opzoeken als voor het aanreiken van de delen werd door het departement van koophandel en koloniën een douceur beschikbaar gesteld en daarmede was voor het hoofd van het departement Falck de zaak af. Hij adviseerde de Koning de nodige orders voor de overgifte van de stukken te geven (Falck aan de Koning I6/I I8I8, Staatssecr. 635).

Bij besluit van de Koning van 20 juni I8I 8 no. 5I (Staatssecr. 635 ) wordt dan de afstand geregeld. De rentmeester van de domeinen te Middelburg wordt gemachtigd de archivalia ter beschikking van de minister van buitenlandse zaken te stellen. In de brief die Van Nagell I7 juli I8I8 tenslotte verzendt ter beantwoording van Clancarty's verzoek van 27 december $18 \mathrm{I} 7$ is geen enkele van Goldberg's argumenten overgenomen, maar volgt een afstand zonder enige restrictie.

Het betreft hier 49 delen, overeenkomende met de lijst, vervat in Goldberg's laatste schrijven van I6 juni I8r8. Drie van de oudste delen over Essequebo uit de jaren I676-1699, benevens de zeven delen copie-notulen zijn, dank zij Goldberg, in het archief van de Kamer Zeeland blijven berusten. Door de geringe werkelijke kennis of voorgewende onwetenheid die men in Neder-, land van de organisatie van de voormalige West Indische Compagnie had, bleef de afstand beperkt tot de stukken van de kamer Zeeland, echter wel het belangrijkste deel van de archieven en het beste bewaard.

Niet verloren gingen de archivalia betreffende Essequebo en Demerary in het archief van de directeuren der Compagnie, de Heren X, noch van die in de archieven van de kamers Amsterdam en de Maze, maar deze stukken zijn vooral voor de oudere periode slechts zeer fragmentarisch aanwezig. En zelfs de overgifte van de Zeeuwse stukken geschiedde niet al te consequent. Behalve de reeds genoemde oudste stukken en notulen is ook de loonadministratie achtergebleven. Evenmin zijn losse stukken betreffende Essequebo en Demerary overgedragen, behorende tot de archieven der verschillende kamers; deze moeten bij een nieuwe inventarisatie in het archief der West Indische Compagnie in het Algemeen Rijksarchief worden ingevoegd, maar zijn daar nu nog te vinden in een collectie "Verspreide West Indische stukken".

Begin september $\mathrm{I} 8 \mathrm{I} 8$ was de Britse regering in het bezit der archivalia van Essequebo en Demerary gesteld. Een ambtenaar 
van de Britse ambassade, Richard PACKenham, ontving ze uit handen van de rentmeester der domeinen van Walcheren, A. STEUR, en bij de eerstvolgende scheepsgelegenheid werden ze naar Engeland verzonden. Over de procedure van overgifte zijn in het archief van buitenlandse zaken nog een aantal brieven bewaard (B.Z. I68, I69, I7I, 3II en 3I2).

De Britse regering was tevreden, maar nog niet voldaan. Haar verlangens richtten zich nu op de documenten betreffende Berbice; I6 sept. I8I8 dringt Clancarty aan op afgifte van ook die stukken (brief I8/9 I8I8, minister B.Z. aan minister van onderwijs, nijverheid en koloniën, B.Z. 312).

Weer is het Falck, die deze kwestie in eerste instantie te behandelen krijgt. In zijn brief van 6 oktober I8I8 kan hij de minister van buitenlandse zaken de lotgevallen van deze archivalia melden. Hem is nu bekend, dat Berbice tot 1796 onder een afzonderlijke en particuliere directie heeft gestaan, buiten invloed van de West Indische Compagnie. In I796 was de directie opgeheven en kreeg de Compagnie het beheer over de kolonie, die daarop de archieven van de directie overnam. Bij de overeenkomst met Engeland van I2 augustus I8I5 over de handel van Nederlandse ingezetenen met de koloniën Essequebo, Demerary en Berbice (Lagemans I, p. I40-I49) was de voormalige directie weer gesteld 'in het 'bezit van vier plàntáges, Dâgêrāâd,' Dankbaarheid, Johanna en Sandvoort (art. II, p. I47-I48). Ten gevolge hiervan waren de archieven door de Nederlandse regering overgegeven aan de herleefde directie. De Britse regering diende zich tot die rechthebbenden te wenden (Falck aan minister B.Z. 6/10 I8I8, B.Z. I72). Men zou de directie van het verzoek van de Britse regering op de hoogte stellen (minister B.Z. aan depart. onderwijs, nijverheid en koloniën 29/Io I8I8, B.Z. 3I2).

De afstand geschiedde echter verder door bemiddeling van het departement van onderwijs, nijverheid en koloniën: $3 \mathrm{I}$ december 1818 meldt Falck aan de minister van buitenlandse zaken, dat $7 \mathrm{I}$ banden (gespecificeerd op een bijgevoegde lijst) gereed zijn voor afgifte (zie ook brief B.Z. aan de Koning 5/I I8I9 en het besluit van de Koning 6/I I8I9, La. Q3 no. 76, Staatssecr. 749). Van enige bedenkingen is dan in het geheel geen sprake meer.

Van de directie van Berbice na haar wederoprichting is geen archief bewaard, zodat wij de mening der directeuren over het verzoek van de Britse regering niet kennen. Toch schijnen deze directeuren, beheerders slechts over een viertal plantages - alles 
wat nog restte aan Nederlands bezit in deze bloeiende kolonie het belang van hun oude archieven te hebben ingezien, getuige de keuze van de stukken, die zij voor afstand in aanmerking lieten komen. Aan de druk van de Nederlandse regering hebben zij zich natuurlijk niet kunnen onttrekken, maar bij hun keuze hebben zij zich voornamelijk beperkt tot die documenten, die het inwendig bestuur van de kolonie betroffen. In Berbice was het namelijk gewoonte geweest, meer dan dat dit geval was in de andere koloniën, deze stukken in origineel èn in copie naar Nederland te zenden. Wij kunnen het betreuren, dat ook van de Berbice archieven zoveel voor Nederland verloren is gegaan, maar zeker treft de directeuren hierbij geen blaam.

De wijze echter, waarop deze afstand van archivalia is behandeld, belicht het weinige inzicht dat men in het begin van de rgde eeuw in Nederland over archivistische kwesties had, al waren er gunstige uitzonderingen, met name Goldberg, wiens adviezen intussen geen enkele invloed hebben gehad. Bovenal wijst deze gang van zaken op een totaal gemis aan belangstelling voor de Nederlandse geschiedenis overzee, en in dit bepaalde geval, voor de geschiedenis van een aantal Nederlandse vestigingen, die in de r8de eeuw zeker voor Nederland van economisch belang zijn geweest.

PUBLIC RECORD OFFICE

List Colonial Office p. $265{ }_{35} \mathrm{C}(\mathrm{D}-\mathrm{H})$

GUIANA, BRITISH

C.O. II6, 18/66 Dutch Association Papers

I686-I69o

1700

$1705^{-1} 709$

I710-1718

I $719-1720$

I $721-1723$

I 724-1 725

I 726-1 730

I730-1733

I 734-1737

I 738-1 742

I $742-1745$

I 745-I 747

I 752-1755

1756-1 760

I $760-1763$

I 764-1 766

I 767

I $768-1770$

I770-I771

I 772-1 773

I774

I $774^{-1} 775$

I 775

I775-1776

1776

I776-1777

44
45

46
47 $\quad \mathbf{1 7 7}$

$4^{8} \quad 1778$ 


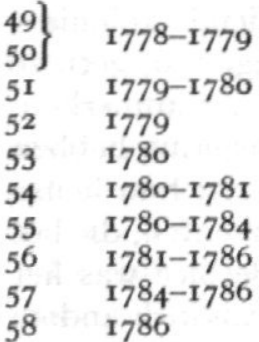

$\begin{array}{ll}59 & \text { I787 } \\ 60 & \text { I787 } \\ 6 \text { I } & \text { I787-1788 } \\ 62 & \text { I788 } \\ 63 & \text { I789-I790 } \\ 64 & \text { I790-I79I } \\ 65 & \text { I790-I79I } \\ 66 & \text { I79I-I792 } \\ 67 & \text { Index }\end{array}$

C.O. II6, 68/136 Berbice

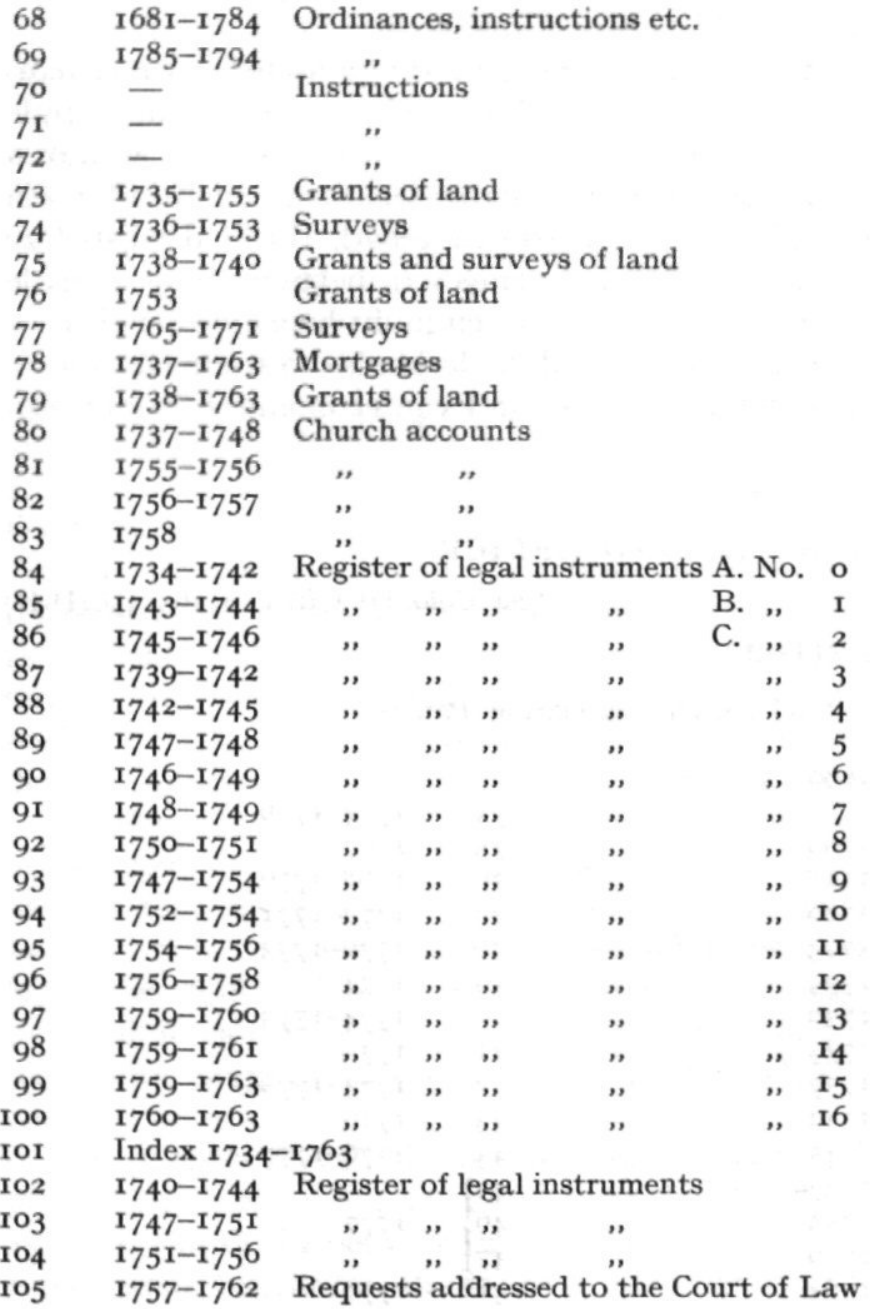


$106 \quad 1764^{-1} 766$ Records of the Court of Policy and Criminal Justice

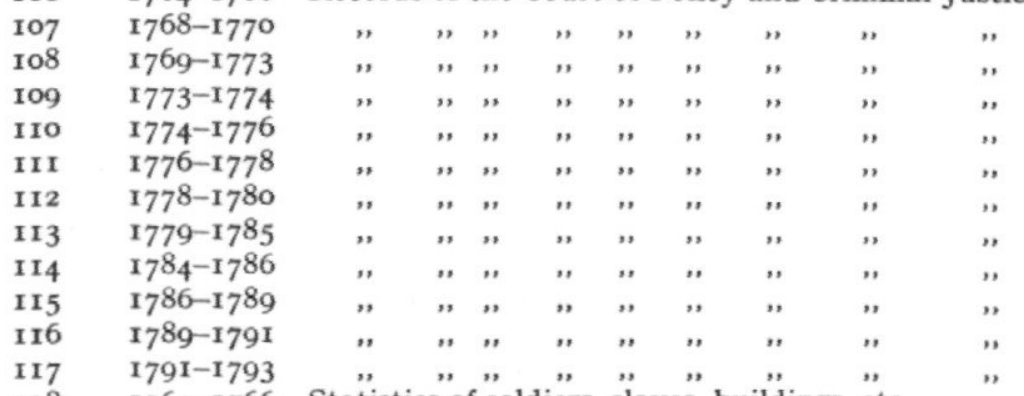

I18 1764-1766 Statistics of soldiers, slaves, buildings, etc.

II9 1766-1770

$120 \quad$ I77 I-I 774

I21 $1774^{-1776}$

$122 \quad 1775-1778$

$123 \quad 1777-1779$

$124 \quad 1779-1785$

I25 1785-1789

I26 I789-179I

I27 I79I-I795

$128 \quad 1765-1771$

$129 \quad$ I77I-I774

130 1774-1777

131 1776-1779

$132 \quad 1779-1786$

I33 I786-1790

I34 I79I-I793

I35 I793-I 794

I36 I765-1790

\begin{tabular}{|c|c|c|c|c|}
\hline " & " & "' & " & ", \\
\hline$"$ & " & " & $"$ & $"$ \\
\hline " & , & " & $"$ & ", \\
\hline " & $"$ & " & $"$ & $"$ \\
\hline ", & ", & " & " & " \\
\hline$"$ & $"$ & $"$ & $"$ & $"$ \\
\hline$"$ & $"$ & " & $"$ & " \\
\hline " & ", & " & $"$ & $"$ \\
\hline & $"$ & $"$ & " & $n$ \\
\hline
\end{tabular}

Taxations, returns, poll-tax, church-tax, etc.

\begin{tabular}{|c|c|c|c|c|c|}
\hline$"$ & ", & $"$ & ", & $"$ & " \\
\hline$"$ & $"$ & $"$ & $"$ & $"$ & $"$ \\
\hline ", & " & $"$ & ", & $"$ & " \\
\hline " & $"$ & $n$ & $"$ & $"$ & " \\
\hline ", & ", & ", & ", & " & ", \\
\hline ", & ", & $"$ & ", & ", & $"$ \\
\hline " & $"$ " & $" n$ & $"$ & $"$ & $"$ \\
\hline
\end{tabular}

\section{SUMMARY}

DOCUMENTS IN THE PUBLIC RECORD OFFICE, LONDON, CONCERNING THE FORMER DUTCH COLONIES OF ESSEQUEBO, DEMERARY AND BERBICE

The Public Record Office in London has a number of documents relating to the administration of the former Dutch colonies of Essequebo, Demerary and Berbice, now British Guiana. They are listed as Colonial Office Papers C.O. 1 16/18-136 and enumerated in the foregoing appendix (p. 137).

Although the 1814 agreement on the transfer of these colonies to the British Crown did not contain any clause concerning the archives, in 1818 the British government requested that they should be handed over, and the Dutch government, without regard to what is known in archival science as 'respect des fonds', complied with the request. 
Accordingly, both West India Company archives from Zeeland concerning Essequebo and Demerary and the separate Berbice archives, were transferred to Great Britain in 1818 and 1819 respectively.

The inter-departmental correspondence concerning the transfer, showing some objections on the part of a few Dutch officials, has been pieced together by the author, after she had traced the use that had been made of the documents in previous research, since no one in the Public Record Office knew more about their origin than could be gathered from the bare inventory.

NeTScher's history of the colonies of Essequebo, Demerary and Berbice (1888) was based on research in the archives in The Hague only, and on published material such as Hartsinck.

BRUGMANs' 1892 report on archives in Great Britain pertaining to Dutch history does not mention the documents in question.

But a member of the United States Commission investigating 'the true divisional line between the Republic of Venezuela and British Guiana' in $1896 / 97$ found that a series of documents on Essequebo in London were exactly those missing from the Netherlands State Archives.

The second part of the nine-volume report of the boundary commission contains extracts from both series of documents, those in The Hague and those in London.

The same can be said of HARRIS and DE VILLIERs' edition of the letters of Governor Storm van 's Gravesande, 1738-1772 (Hakluyt Society, I9II). But here also the publication concerns only a narrow selection from the abundant material.

Eventually a letter dated 1819 from the British Consul in Amsterdam quoted in the Introduction to the Calendar of State Papers, Colonial Series, I9Io, and 'mentioning the transtér of 'the Nẻtherlànds̉ dỏcuments to the Public Record Office, gave the author a clue towards finding the rest of the pertinent correspondence. 